\title{
ENERGY AND MATERIAL ASSESSMENT OF MUNICIPAL SEWAGE SLUDGE APPLICATIONS UNDER CIRCULAR ECONOMY
}

\author{
ANDREY KISELEV ${ }^{1,2}$, IRINA GLUSHANKOVA ${ }^{3}$, LARISA RUDAKOVA ${ }^{3}$, ANDREY BAYNKIN ${ }^{3}$, \\ ELENA MAGARIL ${ }^{1} \&$ ELENA CRISTINA RADA ${ }^{4}$ \\ ${ }^{1}$ Department of Environmental Economics, Ural Federal University, Russia. \\ ${ }^{2}$ Department of Investment Program, Municipal Unitary Enterprise for Water Supply and Sewerage, Russia. \\ ${ }^{3}$ Department of Environmental Protection, Perm National Research Polytechnic University, Russia. \\ ${ }^{4}$ Department of Theoretical and Applied Science, University of Insubria, Italy.
}

\begin{abstract}
In the last decades, the amount of municipal sewage sludge generation rate has drastically increased due to population growth, spatial sewerage system development, and implementation of new treatment techniques. Nowadays, it is considered a globally prominent issue. Municipal sewage sludge contains pathogenic bacteria and viruses along with heavy metals, poorly biodegradable organic compounds, pharmaceuticals, and microplastics, which make its utilization management quite difficult. Landfill placement of sewage sludge is the most widely used technique worldwide, but is obsolete and inefficient, and accompanied by significant risk of environmental pollution with high logistics expenditure. Moreover, landfill placement means that all residual energy and potential material reuse applications are lost. The introduction of modern treatment techniques can solve the problem with sewage sludge generation, but it results in strong energy consumption increase of energy consumption. Modernization and operational policies based on circular economy principles are focused on relevant sewage sludge utilization issues with the potential use of waste-to-energy and recycling applications. The paper presents a methodological approach of cradle-to-grave assessment of sewage sludge treatment process based on energy and material flow analysis. The proposed methodology is studied within the real operational activities of big-scale wastewater treatment plants of two of the largest cities of Russia - Ekaterinburg and Perm. This investigation provides an efficient managerial tool for sustainable development that can be used by wide range of stakeholders.
\end{abstract}

Keywords: anaerobic digestion, assessment, circular economy, pyrolysis, sewage sludge, sludge drying, waste-to-energy.

\section{INTRODUCTION}

Modernization policy planning and implementation of municipal wastewater treatment plants (WWTPs) in order to reduce negative environmental impact is a key element for a sustainable management in concordance with circular economy (CE) view [1-3]. Evolution of rapid techniques together with the development of fundamentally new sludge-processing stages thereby lead to energy consumption growth [4-6].

Achievement of net zero energy at WWTP by utilizing energy efficiency opportunities, combined heat and power (CHP) systems, and other renewable energy potential sources is generally not a priority for the ordinary public utilities sector, while managers are forced to resolve significant waste generation issues [7]. However, the former one is quite important in the context of global population growth and the intensive way of WWTP improvement, especially in developing countries [8-10].

At present, it has become obvious that existing WWTP operation models, based on the traditional (linear) economic approach, block the resolution of actual modern challenges which humanity will face in the future - environmental deterioration and resource depletion. Implementation of advanced practices is of great importance in order to save the nature, as 
well as achieve economic and energy efficiency results. The adoption of CE practices appears as a timely, relevant, and practical option to meet the goals of sustainable development [11,12]. It can be characterized by a reduced use of renewable and non-renewable inputs and closed loop reuse and recycling of material outputs, thus drastically reducing or eliminating waste and dissipative loss together with the creation of new marketable products $[12,13]$.

Recently, the annual sewage sludge (SS) production has been estimated at 14, 6, 13, and 3 million tons of dry matter per year ( $\mathrm{mt}_{\mathrm{DM}}$ /year) in Europe, China, the United States of America, and Russia, respectively, and further increases have been projected with economic and population growth $[14,15]$.

The process of wastewater treatment (WWT) and the resulting SS require significant energy costs, wherein the major share of it is focused on activated sludge (AS) aeration process (more than 60\%), as well as the pumping and dewatering of SS. The specific energy consumption of biological treatment facilities in Russia per equivalent inhabitant is about 0.1 $\mathrm{kW} \mathrm{h/d}$, and the potential energy consumption for the aeration process throughout the country is $240 \mathrm{MW}$ h $(5800 \mathrm{MW} \times \mathrm{d})$. Reducing energy costs in the field of WWTP is an important and priority task.

The implementation of best available processing and utilization techniques for SS through the maximum use of wa ste-to-energy applications is considered the optimal solution to the described problem. According to published scientific data, the calorific value of SS samples with $80 \%$ moisture is $4 \times 10^{3} \mathrm{~kJ} / \mathrm{kg}$, with $20 \%$ moisture $-25 \times 10^{3} \mathrm{~kJ} / \mathrm{kg}[16,17]$.

Nowadays, the following globally recognized SS treatment waste-to-energy techniques are applied at progressive WWTPs: anaerobic digestion (AD), combustion, pyrolysis, and gasification, as reported in Fig. 1 [15]. Considering the high content of organic substances, the coking process could be applied for SS treatment using the developed technology of organic municipal solid waste processing or integrated technologies [18-20].

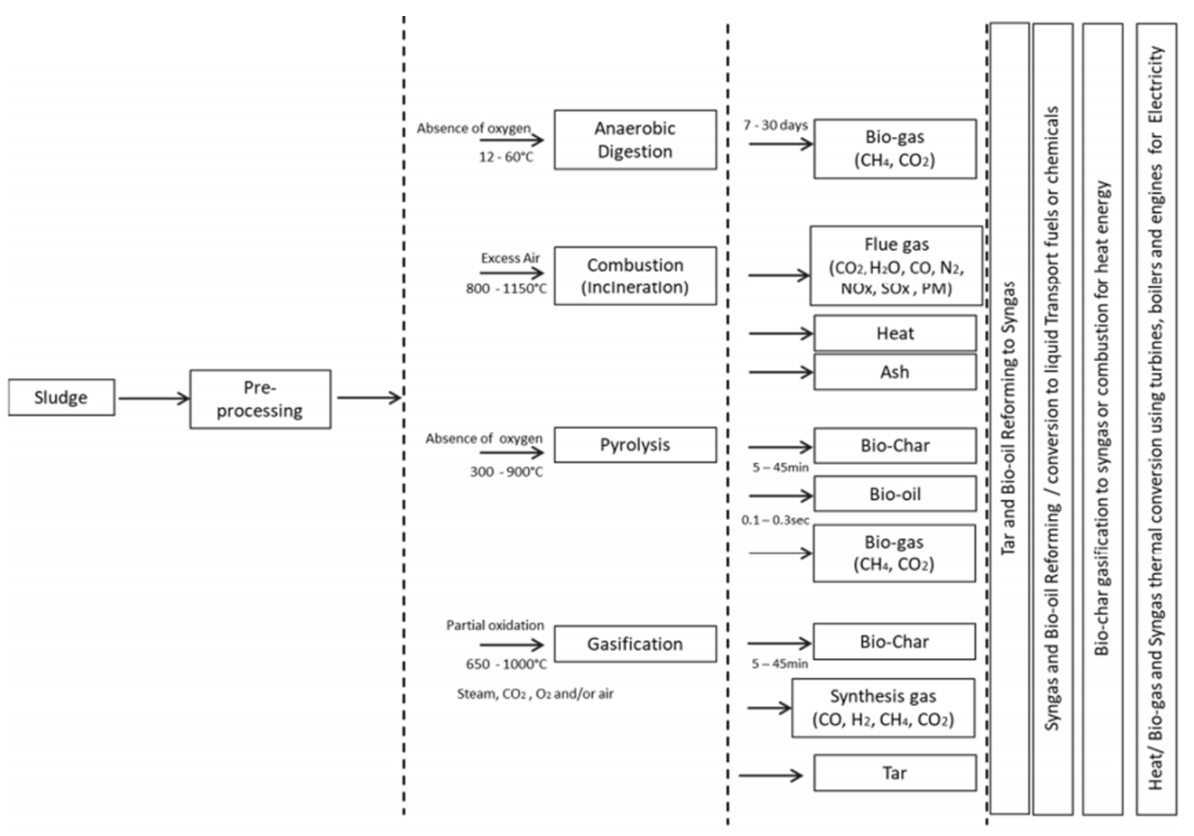

Figure 1: Potential sewage sludge treatment waste-to-energy techniques. (Source: [15]) 
The development of methodological approaches for making a reasonable selection from SS waste-to-energy alternatives will significantly increase the profitability of WWTPs and reduce energy costs for technological processes.

The most common approach for assessment of SS treatment process under CE is Life Cycle Assessment (LCA) [21-24]. Material flow analysis (MFA) is considered to be reasonable for the assessment of WWTP under CE [25, 26].

Nowadays, there is no relevant comparative survey concerning SS treatment and utilization of successful application alternatives, focused on the transition toward $\mathrm{CE}$ at big-scale WWTPs. The purpose of this paper is to create a cradle-to-grave assessment framework using an LCA and MFA construction methodology through energy and SS flows via scenarios under $\mathrm{CE}$ view.

\section{MATERIALS AND METHODS}

The research was performed by applying the basic LCA and MFA to empirical samples collected by the authors at WWTPs. The methodological approach is based on several steps, including: (i) investigated scenarios description; (ii) methodological framework construction; and (iii) results output and visualization.

\subsection{Investigated scenarios}

The authors selected three typical scenarios for wastewater sludge treatment techniques, which are presented in Fig. 2; these correspond to real WWTP operating in two of the largest cities of Russia with a population over 1 million inhabitants.

The first scenario, 'basic', is used at the southern WWTP in Ekaterinburg. The plant receives up to $85 \%$ of the total wastewater inflow from the city; its maximum performance is equivalent to $550,000 \mathrm{~m}^{3} / \mathrm{d}$. The technological process under consideration consists of pumping, thickening, and averaging (PTA) of primary sludge (PS) and waste-activated silt (WAS), with further mechanical dewatering at the chamber filter press. Special chemicals, such as calcium oxide $(\mathrm{CaO})$, are added to increase the efficiency of water loss. Nowadays, the cake $(\mathrm{CA})$ is placed at the landfill, and it means that all the residual energy is lost. Moreover, biodegradation of

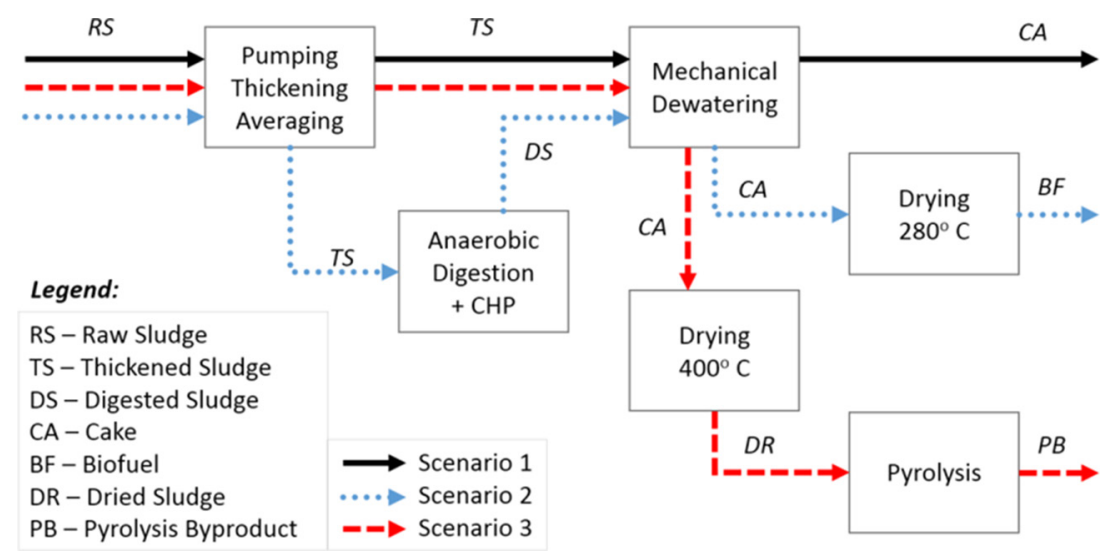

Figure 2: Scenarios under consideration. Scenario 1: based on southern WWTP in Ekaterinburg, Russia; scenario 2: based on northern WWTP in Ekaterinburg, Russia; and scenario 3: based on WWTP in Perm, Russia. 
sludge in the landfills results in the deposition of large amount of hazardous substances and heavy metals into groundwater and soil, despite the special site preparation [27].

The second scenario, 'intensive with drying', assumes a partially circular framework. This pattern is used at the northern WWTP in Ekaterinburg, which receives up to $15 \%$ of a total wastewater inflow from the city; its maximum performance is equivalent to $100,000 \mathrm{~m}^{3} / \mathrm{d}$. The technological process is similar to that of the first scenario, but AD with CHP generation and CA drying is added. AD is used to achieve the required 'sterilization' or pathogen kill, reducing the dry matter of SS f or disposal and producing a methane-rich biogas [28]. Thickened and averaged mixture of PS and WAS is transported into the two digesters with mesophilic digestion process. Biogas from AD is used at the CHP unit produced by Jenbacher with $635 \mathrm{~kW}$ total electrical output and $674 \mathrm{~kW}$ total thermal output. Digested sludge is fed for mechanical dewatering and then for low-temperature drying (at $280^{\circ} \mathrm{C}$ ). Drying is performed by passing the sludge through turbo-drying units, where a thin sediment layer is created along the heated cylinder due to centrifugal force. At the end point, sludge with approximately $80 \%$ of dry matter is compressed into granules and can be used as biofuel for Portland cement clinker production. Cement kiln at $2000^{\circ} \mathrm{C}$ creates preconditions for complete energy and material utilization of sludge: the combustible part is used for heat generation, while the non-combustible part (ash) is used as a cement additive. According to Grilc et al. [29], the average net calorific value of dry sludge is approximately $10,250 \mathrm{MJ} / \mathrm{kg}$ or 2847.22 $\mathrm{kW} \mathrm{h} / \mathrm{kg}$.

The third scenario, 'intensive with pyrolysis', is used at WWTP in Perm. The maximum performance of current WWTP is 400,000 $\mathrm{m}^{3} / \mathrm{d}$. Approximately 1800-2000 tons of raw sludge with $98 \%$ moisture is formed as a result of the daily WWT process. Pre-averaged and thickened raw sludge is forwarded to dewatering process on decanter centrifuges, where it is dehydrated to $75 \%$ moisture. Thereafter, one part is transported to landfills, while another part goes to the pilot facility for thermal treatment, where it is dried and gasified. SS drying is carried out in a cylinder-type installation under the influence of heat-driven substance flue gas with a temperature of up to $400^{\circ} \mathrm{C}$ that originated through pyrolysis/gasification process. The dried sludge is fed to the pyrolysis/gasification reactor. The latter one is designed on the basis of multi hearth furnace (MHF). Dried sludge enters the top of the reactor, where continuous movement of material from overlying hearths to underlying ones is ensured through rotation of the shaft with the blades. Ash is discharged from the bottom of the reactor. The reactor requires an external heat source for heating (diesel) when starting up; then the reactor operates in an autothermal mode without heat consumption. Thus, the reactor moves from pyrolysis to gasification.

In the MHF, the organic part of sludge is completely transformed into generator gas, while the mineral part is discharged in the form of ash. Generator gas is supplied for combustion in a high-temperature gas jet (GJ). The use of external GJ enables volumetric oxidation of the generator gas in the combustion chamber at a temperature of more than $1100^{\circ} \mathrm{C}$. Further combustion gas is fed to the vortex mixer, where it is cooled by cold vapor from the dryer. Thus, the heat-driven substance of appropriate temperature is prepared and then transferred to the dryer.

The vapor from the dryer is partially returned for diluting and cooling the combustion gases inside the vortex mixer. Later, the excess vapor is removed from the dryer and sent to the scrubber for cleaning, where dust particles and gaseous pollutants (compounds of chlorine, fluorine, and sulfur) are removed. Before emission through exhaust pipe, the resulting vapor is condensed and combustion gases are dried. 
The amount of thermal energy obtained by burning the generator gas is sufficient to ensure the process of autothermal drying of SS. Thermal energy for the initial heating of the reactor and electric power to drive the mechanisms of the complex, which are taken from outside, make up only a minor part in comparison with the energy consumption for SS drying. This heat consumption is not taken into account via methodological framework. All SS will be subjected to pyrolysis/gasification after trial exploitation.

\subsection{Methodological framework}

LCA is linked to the international environmental management standard ISO 14000 and is capable of assessing from raw material acquisition for product manufacturing to utilization, end-of-life treatment, and final disposal [30]. LCA comprehensively considers the current and potential influence of a system on the environment through cradle-to-grave analysis. The LCA step-by-step action plan described in ISO 14040:2006 includes four consistent stages: (i) goal and scope definition; (ii) inventory analysis; (iii) impact analysis; and (iv) interpretation of results.

MFA is considered a relevant tool for environmental sustainability assessment and management, which is closely associated with CE principles. It is a quantitative procedure for determining the flow of materials and energy through the economy. It captures the mass balances in an economy where inputs (extractions + imports) equal outputs (consumption + exports + accumulation + wastes) [31].

The investigation conducted in the present work is based on the principles of LCA and MFA considered in a single framework. These methods create opportunities to draw energy and material balance of WWTP in order to improve sustainable management under CE paradigm. Framework application will help to create a sound environment for managerial decision-making during development of operational and modernization policies. Application of the MFA tool together with LCA creates a simple and intuitive method which provides holistic cradle-to-grave assessment of SS treatment process under specific system boundaries in quest for the best management benchmark.

The flows of energy and SS, including PS and WAS, were measured during 1 year (2018) and expressed in daily values $(\mathrm{kW} \mathrm{h/d}$ and tons/d) throughout the different scenarios. The current investigation is focused on total mass reduction and energy balance (consumed/generated) for this process; no emissions were estimated. To evaluate the energy balance, the net energy consumption (NEC) indicator was used; this is calculated by subtracting the energy content of the secondary fuels and energy commodities produced from the operation of the facility from the total energy consumed by the operation of a facility, using the following equation [7]:

$$
N E C=E C-E G,
$$

where $E C$ is the energy consumed from the grid (including electrical and thermal) and $E G$ is the energy generated throughout the technological process or potential energy, which can be generated somewhere beyond the boundaries of current scenarios (e.g. dried SS can be used as a biofuel at the cement kiln).

\subsection{Results interpretation}

The Sankey diagram can be used as an effective post-processing tool to focus on energy and mass flows and their transformation across various systems. It is expressed by arrows whose 
width represents the magnitude of the flow [32]. Energy and material system boundaries are associated with temporal and spatial dimensions.

The Sankey diagram outputs are focused on energy efficiency and waste reduction through reuse and recycle applications and creation of closed loops. The way toward CE offers possibilities for a company to become energy positive with significantly lower than the original SS volume. Transparent and natural visualization of key elements of SS treatment and utilization techniques creates opportunities for managers to strive for technological improvements through rethinking and redesigning the operating system itself.

Despite the fact that WWTPs under consideration collect wastewater from among the largest cities of Russia with a population of over 1 million inhabitants, each facility has its own scale. To compare the data obtained at different WWTPs, the following averaged indicators are used: mass decrease efficiency (MDE), average energy consumption (AEC), and average net energy consumption (ANEC).

The MDE indicator reveals the percentage of SS obtained as a result of technological process compared to the initial raw sludge inflow and is calculated as follows:

$$
M D E=\frac{M_{F S}}{M_{R S}},
$$

where $M_{F S}$ is the total mass of SS, resulting from a cradle-to-grave technological cycle, and $M_{R S}$ is the total mass of initial raw SS.

The AEC indicator shows the amount of energy consumed for the SS treatment process relative to the mass of initial raw SS. AEC can be calculated both for the whole process and for its part. This indicator is calculated using the following equation:

$$
A E C=\frac{E C}{M_{R S}},
$$

where $E C$ is the energy consumed from the grid and $M_{R S}$ is the total mass of initial raw SS.

The ANEC indicator is defined similarly to AEC; however, NEC is used instead if energy consumption (E C). This indicator is calculated using the following equation:

$$
A N E C=\frac{N E C}{M_{R S}},
$$

where $N E C$ is the net energy consumption, calculated using eqn (1), and $M_{R S}$ is the total mass of initial raw SS. Both AEC and ANEC indicators were advisedly used in order to demonstrate how the renewable energies affect the energy balance of WWTP.

\section{RESULTS AND DISCUSSION}

The Sankey diagram with obtained results for scenario 1 is presented in Fig. 3. It should be noted that the current pattern is typical for most of the WWTPs in Russia. The MDE indicator, calculated with eqn (2), is $10.65 \%$, and this is quite enough to ensure WWTP operation activities, nothing more. CA is transported to specially prepared landfills to remove waste from the territory of WWTP and to eliminate the negative impact on human health and environment. However, all the potential energy is irrevocably lost. The energy consumption for PTA stage is several times higher than the one for mechanical dewatering stage. For this reason, the managers have to consider energy efficiency improvement as a priority goal for WWTP. 


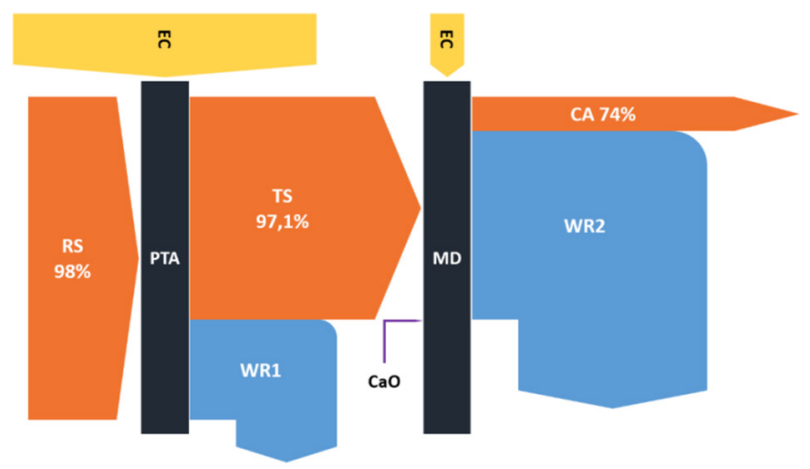

Figure 3: Energy and material Sankey diagram for scenario 1.

Contaminated wastewater resulting from the separation of liquid and solid phases (WR1 and WR2) is returned to the main WWT process. However, depending on the regulations, it can be used locally for water reclamation as a possible solution for the problem of water scarcity $[2,33]$.

The results obtained for the second scenario reveal a more advanced SS treatment and utilization technique as presented in Fig. 4.

The total MDE for cradle-to-grave process is $2.41 \%$. However, it can be assumed that MDE is equal to $0 \%$ since the resulting dried sludge after being used at the cement kiln as a biofuel ceases to exist as a waste through energy and material transformation. Significant energy consumption can be seen at the sludge drying process, and this is very typical because heating up to $280^{\circ} \mathrm{C}$ is required. On the other hand, additional energy can be received from the CHP unit operation and biofuel utilization.

An analysis of the results obtained for the third scenario, which is presented in Fig. 5, shows that the MDE indicator for the pyrolysis/gasification process is $4.5 \%$. The pyrolysis/ gasification end product is ash, which is an inorganic residue containing silicon dioxide, poorly soluble phosphates (up to 5\%-6\%), and heavy metal ions. It is possible to use ash as a complex mineral fertilizer through specific recovery methods; therefore, the MDE indicator can be significantly reduced.

To assess the specific performance indicators for all scenarios under consideration, MDE, AEC, and ANEC results were plotted on a single graph presented in Fig. 6. It can be noticed that the outputs of the second scenario can be highlighted for the achievement of net zero consumption at WWTP.

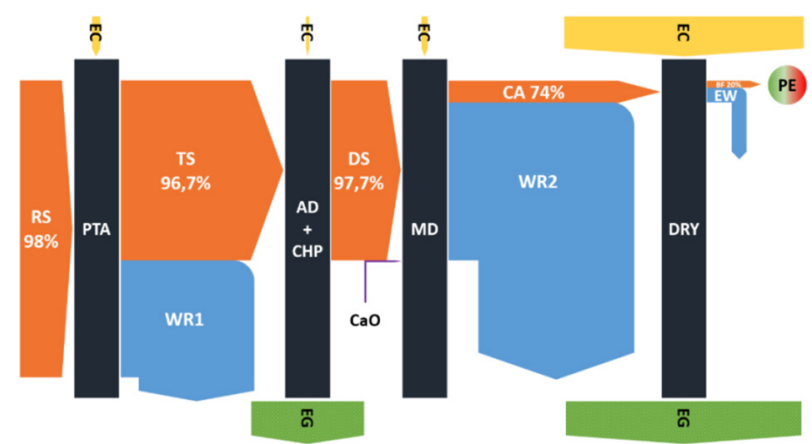

Figure 4: Energy and material Sankey diagram for scenario 2. 

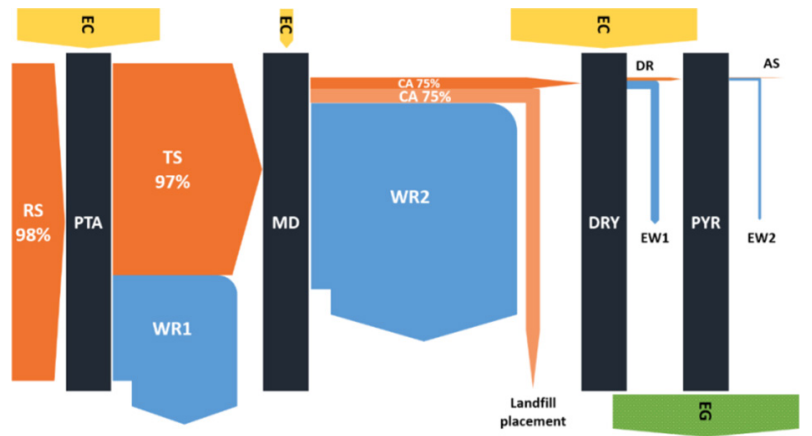

Figure 5: Energy and material Sankey diagram for scenario 3.

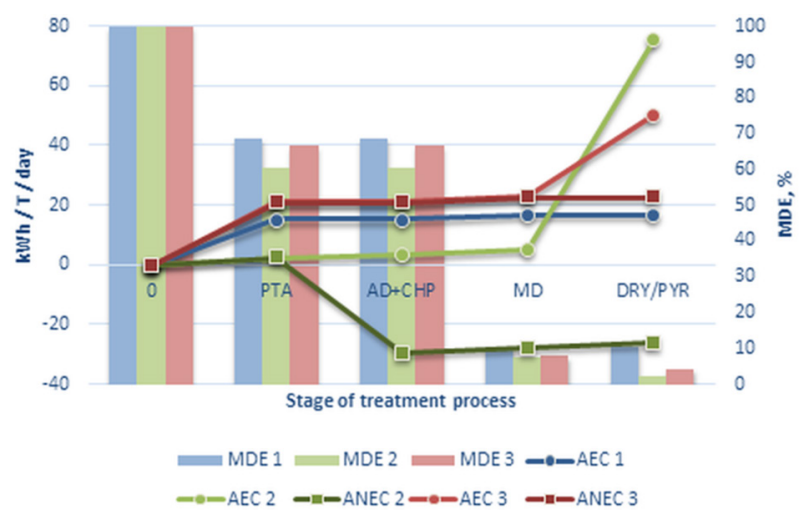

Figure 6: Mass and energy efficiency outputs.

With respect to the third scenario, it must be considered that the current gasification process is under test operations, and nowadays, the generator gas, originating from the organic component of SS, is completely spent on the CA drying process. After commissioning, additional energy from the generator gas is expected.

A similar result for scenario 3 could be obtained if an AD technique together with CHP unit will be introduced at WWTP in Perm. Before this point, the specific energy consumption for scenario 3 exceeds that for scenario 1, although the mass reduction is more efficient.

Despite the visual results, the proposed model has a number of assumptions and simplifications. The heating costs for buildings and structures serving the technological process for all the stages were not considered. The achievement of net zero consumption at WWTP goes beyond the boundaries of the research presented in this paper, as it includes energy consumption for the main WWT process whereas there is practically no opportunity to generate energy. An extended study of this phenomenon should be carried out in future.

\section{CONCLUSION}

A practical application of the proposed method creates a strong but simple tool for managers to work on the transition toward CE view application in WWTP. All possible main flows of energy and materials can be taken into account and analyzed for the possibilities of creating recycling loops. In case of alternative SS technological solutions, this approach will help to determine the most sustainable option. Furthermore, the progress can be tracked toward a net zero consumption throughout the national benchmarking system. 


\section{ACKNOWLEDGMENT}

This research was supported by Act 211 Government of the Russian Federation, contract No. 02.A03.21.0006.

\section{REFERENCES}

[1] Gherghel, A., Teodosiu, C., Notarnicola, M. \& De Gisi, S., Sustainable design of large wastewater treatment plants considering multi-criteria decision analysis and stakeholders' involvement. Journal of Environmental Management, 261, 110158, 2020. https:// doi.org/10.1016/j.jenvman.2020.110158

[2] Kiselev, A., Magaril, E. \& Rada, E.C., Energy and sustainability assessment of municipal wastewater treatment under circular economy paradigm. WIT Transactions on Ecology and the Environment, 237, pp. 109-120, 2019. https://doi.org/10.2495/ESUS190101

[3] Casiano Flores, C., Bressers, H., Gutierrez, C. \& de Boer, C., Towards circular economy - a wastewater treatment perspective, the Presa Guadalupe case. Management Research Review, 41(5), pp. 554-571, 2018. https://doi.org/10.1108/MRR-02-2018-0056

[4] Capodaglio, A.G. \& Olsson, G., Energy issues in sustainable urban wastewater management: Use, demand reduction and recovery in the urban water cycle. Sustainability, 12(1), 266, 2020. https://doi.org/10.3390/su12010266

[5] Yu, Y., Zou, Z. \& Wang, S., Statistical regression modeling for energy consumption in wastewater treatment. Journal of Environmental Sciences, 75, pp. 201-208, 2019. https://doi.org/10.1016/j.jes.2018.03.023

[6] Langone, M., Ferrentino, R., Trombino, G., Waubert De Puiseau, D, Rada, E.C. \& Ragazzi, M., Application of a novel hydrodynamic cavitation system in wastewater treatment plants. UPB Scientific Bulletin, Series D, 77(1), pp. 225-234, 2015.

[7] Yan, P., Qin, R.-C., Guo, J.-S., Yu, Q., Li, Z., Shen, Y. \& Fang, F., Net-zero-energy model for sustainable wastewater treatment. Environmental Science and Technology, 51(2), pp. 1017-1023, 2017. https://doi.org/10.1021/acs.est.6b04735

[8] Awad, H., Gar Alalm, M. \& El-Etriby, H.K., Environmental and cost life cycle assessment of different alternatives for improvement of wastewater treatment plants in developing countries. Science of the Total Environment, 660, pp. 57-68, 2019. https://doi. org/10.1016/j.scitotenv.2018.12.386

[9] Hares, M. \& Dayem, M. Abdel, Difficulties encountered in executing and running of waste water plants in developing countries, Coating Conference, Proceedings of the Technical Association of the Pulp and Paper Industry, pp. 175-185, 2017.

[10] Ragazzi, M., Catellani, R., Rada, E.C., Torretta, V. \& Salazar-Valenzuela, X., Management of urban wastewater on one of the Galapagos Islands. Sustainability, 8(3), 208, 2016, https://doi.org/10.3390/su8030208

[11] Saidani, M., Yannou, B., Leroy, Y., Cluzel, F. \& Kendall, A., A taxonomy of circular economy indicators. Journal of Cleaner Production, 207, pp. 542-559, 2019. https:// doi.org/10.1016/j.jclepro.2018.10.014

[12] Pinter, L., International Experience in Establishing Indicators for the Circular Economy and Considerations for China, Report for the Environment and Social Development Sector Unit, East Asia and Pacific Region, The World Bank, 2006. Online https:// www.iisd.org/sites/default/files/publications/measure_circular_economy_china.pdf Accessed on: 22 Feb. 2020.

[13] Lind, M., Witherspoon, J., Gokul, B. \& Surti, J., From wastewater treatment to total resource recovery - Changes are happening in Auckland, NZ, 86th Annual Water Environment Federation Technical Exhibition and Conference, 9, pp. 5729-5747, 2013. 
[14] Oladejo, J., Shi, K., Luo, X., Yang, G. \& Wu, T., A review of sludge-to-energy recovery methods. Energies, 12(1), 60, 2019. https://doi.org/10.3390/en12010060

[15] Kiselev, A., Magaril, E., Magaril, R., Panepinto, D., Ravina, M. \& Zanetti, M.C., Towards circular economy: Evaluation of sewage sludge biogas solutions. Resources, 8(2), 91, 2019. https://doi.org/ 10.3390/resources8020091

[16] Turovskiy, I.S., Sewage Sludge. Dewatering \& Disinfection, DeLi Print Publ.: Moscow, 375 p., 2008.

[17] Bernadiner, I.M., Stepanova, T.A., Klyuchniko, A.D., Chevychelov, D.D., Khoreva, P.V., Nikolayev, D.A., Toumanovsky, V.A. \& Bernadiner, M.N., Thermal methods of sewage sludge neutralization. Ecology and Industry of Russia, 7, pp. 4-7, 2012 (In Russ.).

[18] Paukov, A., Magaril, R. \& Magaril, E., An investigation of the feasibility of the organic municipal solid waste processing by coking. Sustainability, 11(2), 389, 2019. https:// doi.org/ 10.3390/su11020389

[19] Merzari, F., Langone, M., Andreottola, G. \& Fiori, L., Methane production from process water of sewage sludge hydrothermal carbonization. A review. Valorising sludge through hydrothermal carbonization. Critical Reviews in Environmental Science and Technology, 49(11), pp. 947-988, 2019. https://doi.org/10.1080/10643389.2018.1561 104

[20] Rada, E.C., Ragazzi, M., Villotti, S. \& Torretta, V., Sewage sludge drying by energy recovery from OFMSW composting: Preliminary feasibility evaluation. Waste Management, 34(5), pp. 859-866, 2014. https://doi.org/1010.1016/j.wasman.2014.02.013

[21] Pintilie, L., Torres, C.M., Teodosiu, C. \& Castells, F., Urban wastewater reclamation for industrial reuse: An LCA case study. Journal of Cleaner Production, 139(15), pp. 1-14, 2016. https://doi.org/10.1016/j.jclepro.2016.07.209

[22] Molina-Moreno, V., Leyva-Díaz, J.C., Llorens-Montes, F.J. \& Cortés-García, F.G., Design of indicators of circular economy as instruments for the evaluation of sustainability and efficiency in wastewater from pig farming industry. Water, 9, 653, 2017. https://doi.org/10.3390/w9090653

[23] Buonocore, E., Mellino, S., De Angelis, G., Liu, G. \& Ulgiati, S., Life cycle assessment indicators of urban wastewater and sewage sludge treatment. Ecological Indicators, 94, pp. 13-23, 2018. https://doi.org/10.1016/j.ecolind.2016.04.047

[24] Grönlund, S.E., Indicators and methods to assess sustainability of wastewater sludge management in the perspective of two systems ecology models. Ecological Indicators, 100, pp. 45-54, 2019. https://doi.org/10.1016/j.ecolind.2018.07.013

[25] Papangelou, A., Achten, W. \& Mathijs, E., Phosphorus and energy flows through the food system of Brussels capital region. Resources, Conservation and Recycling, 156, 104687, 2020. https://doi.org/10.1016/j.resconrec.2020.104687

[26] Fisher, R.M., Alvarez-Gaitan, J.P., Stuetz, R.M. \& Moore, S.J., Sulfur flows and biosolids processing: Using material flux analysis (MFA) principles at wastewater treatment plants. Journal of Environmental Management, 198, pp. 153-162, 2017. https://doi. org/10.1016/j.jenvman.2017.04.056

[27] Yuan, H., Xing, S., Lu, T., Huhetaoli, Chen, Y. \& Kobayashi, N., Main organic pollutants migration and transformation laws in sewage sludge landfill and composting process. WIT Transactions on Biomedicine and Health, 18, pp. 1183-1190, 2014. https:// doi.org/10.2495/HHME131342 
[28] Mills, N., Pearce, P., Farrow, J., Thrope, R.B. \& Kirkby, N.F., Environmental \& economic life cycle assessment of current \& future sewage sludge to energy technologies. Waste Management, 34, pp.185-195, 2014. https://doi.org/10.1016/j.wasman.2013.08.024

[29] Grilc, V., Mislej, V. \& Šalej, S., Thermal utilisation of biologically stabilised and dried waste sludge from wastewater treatment plants. 3rd International Symposium on Energy from Biomass and Waste, Venice, 2010.

[30] Chen, G., Wang, X., Li, J., Yan, B., Wang, Y., Wu, X., Velichkova, R., Cheng, Z. \& Ma, $\mathrm{W}$., Environmental, energy, and economic analysis of integrated treatment of municipal solid waste and sewage sludge: A case study in China. Science of the Total Environment, 647, pp.1433-1443, 2019. https://doi.org/10.1016/j.scitotenv.2018.08.104

[31] Pincetl, S., A living city: Using urban metabolism analysis to view cities as life forms. Metropolitan Sustainability Understanding and Improving the Urban Environment, pp. 3-25, 2012. https://doi.org/10.1533/9780857096463.1.3

[32] Soundararajan, K., Ho, H.K. \& Su, B., Sankey diagram framework for energy and exergy flows. Applied Energy, 136, pp.1035-1042, 2014. https://doi.org/10.1016/j. apenergy.2014.08.070

[33] Trulli, E., Torretta, V. \& Rada, E.C., Water restoration of an urbanized karst stream by free-water-surface constructed wetlands as municipal wastewater post treatment. $U P B$ Scientific Bulletin, Series D, 78(4), pp. 163-174, 2016. 